Anuario da Facultade de Dereito da Universidade da Coruña

Vol. 22 (2018), pp. 329-356

ISSNe: 2530-6324 || ISSN: 1138-039X

DOI: https://doi.org/10.17979/afdudc.2018.22.0.5190

\title{
LA PLANIFICACIÓN Y PROGRAMACIÓN DE LOS CONTRATOS EN LA LEY 9/2017 DE CONTRATOS DEL SECTOR PÚBLICO ${ }^{1}$
}

\author{
MARÍA DEL CARMEN RODRÍGUEZ MARTÍN-RETORTILLO \\ Profesora interina de Derecho Administrativo e Investigadora \\ Universidade da Coruña
}

\begin{abstract}
Resumen: La nueva Ley de Contratos del Sector Público otorga una especial relevancia a la planificación de los contratos y la programación de la actividad contractual. Si bien, todavía resulta insuficiente dado que no se definen el contenido del plan ni de la programación, la periodicidad y las consecuencias de su incumplimiento, así como la necesidad de evaluar a posteriori dicha planificación y programación.
\end{abstract}

Palabras clave: planificación, plan de contratación, programación, previsión, transparencia

\footnotetext{
${ }^{1}$ Al profesor José Luis Meilán Gil, in memoriam, como expresión de reconocimiento, admiración y afecto a un gran maestro.
} 
Abstract: The new Public Sector Contracts Law grants special relevance to the planning of contracts and the programming of contractual activity. Although, it is still insufficient because the content of the plan and the programming, the periodicity and the consequences of its non-compliance are not defined, as well as the need to evaluate subsequently the planning and programming.

Keywords: planning, contracting plan, programming, forecast, transparency

SUMARIO: I. INTRODUCCIÓN. II. LA PLANIFICACIÓN EN LA NORMATIVA CONTRACTUAL HISTÓRICA. III. LA PLANIFICACIÓN EN LOS INFORMES DE LOS CONSEJOS CONSULTIVOS Y JUNTAS CONSULTIVAS DE CONTRATACIÓN. 3.1. PLANIFICACIÓN EN EL ÁMBITO SANITARIO. 3.2. PLANIFICACIÓN EN LA CONTRATACIÓN ESTRATÉGICA. IV. LA PLANIFICACIÓN EN LOS INFORMES DEL TRIBUNAL DE CUENTAS. 4.1. PLANIFICACIÓN DE LAS ENCOMIENDAS. 4.2. PLANIFICACIÓN DE UN TRANVÍA. 4.3. PRESTACIONES REITERADAS. V. LA PLANIFICACIÓN EN LAS DIRECTIVAS DE CONTRATOS. A. DIRECTIVAS HISTÓRICAS. A.1 DIRECTIVA 93/37/CEE DEL CONSEJO, DE 14 DE JUNIO DE 1993, SOBRE COORDINACIÓN DE LOS PROCEDIMIENTOS DE ADJUDICACIÓN DE LOS CONTRATOS PÚBLICOS DE OBRAS. A.2 DIRECTIVA 2004/17/CE DEL PARLAMENTO EUROPEO Y DEL CONSEJO DE 31 DE MARZO DE 2004 SOBRE LA COORDINACIÓN DE LOS PROCEDIMIENTOS DE ADJUDICACIÓN DE CONTRATOS EN LOS SECTORES DEL AGUA, DE LA ENERGÍA, DE LOS TRANSPORTES Y DE LOS SERVICIOS POSTALES. A.3 DIRECTIVA 2004/18/CE DEL PARLAMENTO EUROPEO Y DEL CONSEJO DE 31 DE MARZO DE 2004, SOBRE COORDINACIÓN DE LOS PROCEDIMIENTOS DE ADJUDICACIÓN DE LOS CONTRATOS PÚBLICOS DE OBRAS, DE SUMINISTRO Y DE SERVICIOS. B. DIRECTIVAS VIGENTES. B.1 DIRECTIVA 2014/24/UE DEL PARLAMENTO EUROPEO Y DEL CONSEJO, DE 26 DE FEBRERO DE 2014, SOBRE CONTRATACIÓN PÚBLICA Y POR LA QUE SE DEROGA LA DIRECTIVA 2004/18/CE. B.2 DIRECTIVA 2014/23/UE DEL PARLAMENTO EUROPEO Y DEL CONSEJO DE 26 DE FEBRERO DE 2014, RELATIVA A LA ADJUDICACIÓN DE CONTRATOS DE CONCESIÓN. B.3 DIRECTIVA 2014/25/UE DEL PARLAMENTO EUROPEO Y DEL CONSEJO DE 26 DE FEBRERO DE 2014, RELATIVA A LA CONTRATACIÓN POR ENTIDADES QUE OPERAN EN LOS SECTORES DEL AGUA, LA ENERGÍA, LOS TRANSPORTES Y LOS SERVICIOS POSTALES Y POR LA QUE SE DEROGA LA DIRECTIVA 2004/17/CE. VI. LA PLANIFICACIÓN Y PROGRAMACIÓN EN LA LEY 9/2017, DE CONTRATOS DEL SECTOR PÚBLICO. VII. LA DIVISIÓN EN LOTES COMO ESTUDIO A INCLUIR EN LA PROGRAMACIÓN DE LOS CONTRATOS. 7.1. CONSIDERACIONES PREVIAS. 7.2. PLAN DE CONTRATACIÓN. 7.2.1 PUBLICIDAD DEL PLAN DE CONTRATACIÓN. 7.3. QUÉ SE DEBE PROGRAMAR. 7.3.1 APLICACIONES ADECUADAS.7.3.2. ÁMBITO TEMPORAL. VIII. LA DIVISIÓN EN LOTES COMO ESTUDIO A INCLUIR EN LA PROGRAMACIÓN DE LOS CONTRATOS. IX. LOS ASPECTOS SOCIALES Y 
MEDIOAMBIENTALES EN EL MARCO DE LA PLANIFICACIÓN DE LOS CONTRATOS. X. LAS CONSULTAS PRELIMINARES DE MERCADO COMO INSTRUMENTO PARA LA PLANIFICACIÓN DE LOS CONTRATOS. XI. VINCULACIÓN DE LA PLANIFICACIÓN CON EL PRINCIPIO DE TRANSPARENCIA. XII. UNA ADECUADA PLANIFICACIÓN PUEDE REDUCIR EL VOLUMEN DE LOS CONTRATOS MENORES. XIII. LA TRAMITACIÓN ANTICIPADA DE CONTRATOS. XIV. LA PROGRAMACIÓN ESPECÍFICA EN CADA CONTRATO. XV. FUNCIONES DE LA JUNTA CONSULTIVA DE CONTRATACIÓN PÚBLICA DEL ESTADO EN MATERIA DE PLANIFICACIÓN DE CONTRATOS. XVI. FUNCIONES DE PLANIFICACIÓN DE TRAGSA. XVII. CONCLUSIONES. XVIII. BIBLIOGRAFÍA.

\section{INTRODUCCIÓN}

Si bien es inherente a toda actividad pública la planificación, bien recogida en la normativa sectorial ${ }^{2}$ o bien como técnica organizativa, necesaria, de previsión y anticipación, para cumplir los objetivos y las finalidades públicas ${ }^{3}$, hasta la entrada en vigor de la nueva Ley 9/2017, de 8 de noviembre, de Contratos del Sector Público, por la que se transponen al ordenamiento jurídico español las Directivas del Parlamento

\footnotetext{
${ }^{2}$ Vid., a modo de ejemplo: En la normativa histórica: la Ley de Bases de Obras Públicas de 26 diciembre de 1876 y la Ley General de Obras Públicas de 13 de abril de 1877 (Art.20); el Reglamento de la Ley de Carreteras de 10 de Agosto de 1877 (Art.29); el Real Decreto de 15 de Julio de 1925, por el que se aprueba el Reglamento de Obras y Vías Provinciales (Art.25).

En la normativa actual: la Ley 7/85 de Bases de Régimen Local (Art.4.c) y Art.36, relativo al Plan Provincial de Cooperación); la Ley 37/2015 de Carreteras (Art.7); la Ley 8/2013, de Carreteras de Galicia, (Arts.11-14); el Texto refundido de la Ley de Aguas, aprobado por R. Decreto Legislativo 1/2001 (Arts.40-46); el Reglamento de planificación hidrológica, R Decreto 907/2007, de 6 de julio (Art. 4); el Real Decreto Legislativo 7/2015, de 30 de octubre, por el que se aprueba el texto refundido de la Ley del Suelo y Rehabilitación Urbana; la Ley 2/2016, de 10 de febrero, del Suelo de Galicia (Arts.45 y ss); la Ley 6/2007, de 11 de mayo, de Medidas Urgentes de Ordenación del Territorio y del Litoral de Galicia (Arts.2 y 5); el Real Decreto Legislativo 2/2011, de 5 de septiembre, por el que se aprueba el texto refundido de la Ley de Puertos del Estado y de la Marina Mercante (Arts.52-55); la Ley 42/2007, de 13 de diciembre, del Patrimonio Natural y de la Biodiversidad (Arts.12-14, Arts. 16-24); la Ley 7/2008, de 7 de julio, del Paisaje de Galicia (Arts.8 y 12); la Ley 9/2014, de 9 de mayo, de Telecomunicaciones (Art.20); la Ley 16/1987, de 30 de julio, de Ordenación de los Transportes Terrestres (Art.7.b, Arts.15-16); la Ley 21/1992, de 16 de julio, de Industria (Art.3.6); la Ley 7/2011, de 27 de octubre, de Turismo de Galicia (Arts.22-32); la Ley Orgánica 2/2006, de 3 de mayo, de Educación (Art.143); la Ley 14/86, de 25 de abril, General de Sanidad (Art.70-76); la Ley 13/2008, de 3 de diciembre, de Servicios Sociales de Galicia (Arts.44-48); la Ley 40/2015, de 1 de octubre, de Régimen Jurídico del Sector Público, que regula el Plan anual normativo (Art.25); el Texto refundido de la Ley reguladora de las Haciendas Locales, aprobado por Real Decreto Legislativo 2/2004, de 5 de marzo (Art.166.1.a).

${ }^{3}$ Sebastián Martín-Retortillo apuntaba que "En la legislación del XIX el Plan supone, en primer lugar, expresión de una técnica que facilita a la Administración el conocimiento de una determinada realidad: la técnica planificadora se asume, en tal sentido, como fórmula de representación de unas situaciones de hecho, con el fin de que, precisamente y en base a estos datos, pueda luego la Administración orientar su comportamiento posterior". MARTÍN-RETORTILLO, S., "Antecedentes del concepto de plan y referencia a la legislación de fomento del siglo XX", $R A P, \mathrm{n}$ ○49, enero-abril 1966, pág. 43.
} 
Europeo y del Consejo 2014/23/UE y 2014/24/UE, de 26 de febrero de 2014 (en adelante, LCSP) el legislador no había recogido expresamente en la normativa contractual la necesidad de programar y planificar la actividad contractual. Tan sólo las normas anteriores hacían alusiones a la posibilidad de tramitar expedientes anticipados de gasto y contratos plurianuales, anuncios indicativos, compras centralizadas ${ }^{4}$ o la obligatoriedad de los programas de trabajo en la documentación de los proyectos de obras, pero concebidos de forma aislada para expedientes concretos.

Podemos decir por ello que por primera vez la LCSP recoge como novedad en su texto la necesidad de la programación de la actividad contractual y la obligación de dar a conocer su plan de contratación ${ }^{5}$. Sin embargo, entendemos que aunque es un avance la regulación es insuficiente, como analizaremos a continuación.

Como señala José Luis Meilán Gil "se ha afirmado que la contratación tendría una fase interna y una fase externa. La primera se desarrollaría en el interior de la Administración, que incluiría la preparación y programación o planificación y la segunda tiene relación con los particulares, posibles contratistas, que se iniciaría con el acto que anuncia la licitación para seleccionar el contratista y concluiría con la suscripción del contrato", añadiendo que "de acuerdo con lo expuesto, la denominada fase "precontractual" forma parte del contrato. Para mayor precisión, los actos de preparación o planificación y los de licitación forman parte del contrato".

\section{LA PLANIFICACION EN LA NORMATIVA CONTRACTUAL HISTÓRICA}

En las primeras normas no encontramos referencias a la programación de los contratos. A continuación se enunciarán brevemente aquellos preceptos relacionados con la misma.

\footnotetext{
${ }^{4}$ La Resolución de 17 de junio de 1997, por la que se hace público el Acuerdo del Consejo de Ministros de 6 de junio de 1997, por el que se aprueba el programa de gobierno para la ejecución de una política de compras públicas; la Orden 94/1999, de 26 de marzo, para la elaboración del Plan Anual de Adquisiciones Centralizadas del Ministerio de Defensa (BOE n 83 , de 7 de abril de 1999), donde se preveía en su Art.1 (Ámbito de aplicación) que "El Plan Anual de Adquisiciones Centralizadas comprenderá los bienes consumibles o de fácil deterioro por el uso, de utilización generalizada en los Ejércitos o en el órgano central (...)". Esta orden fue derogada por Orden DEF/2021/2011, de 13 de julio, por la que se regula la contratación centralizada y se modifica la composición y competencias de las Juntas de Contratación del Ministerio de Defensa, del Estado Mayor de la Defensa y de los Ejércitos, que establecía en su Art.10 "El Plan Anual de Contratación Centralizada (PACC)", que definía como el " documento en el que se detallarán las propuestas de contratos incluidos en el ámbito de aplicación del artículo 3, que serán objeto de contratación centralizada por las Juntas de Contratación del Ministerio. Además de la relación y descripción de las obras, bienes y servicios objeto de contratación centralizada, el Plan incluirá el calendario de contratación, la Junta de Contratación responsable de cada contrato y los órganos responsables de elaborar la documentación preparatoria del expediente de contratación y del seguimiento particularizado del acuerdo marco o contrato".

${ }^{5}$ Art.28 de la LCSP (Necesidad e idoneidad del contrato y eficiencia en la contratación):

“(...) 4. Las entidades del sector público programarán la actividad de contratación pública, que desarrollarán en un ejercicio presupuestario o períodos plurianuales y darán a conocer su plan de contratación anticipadamente mediante un anuncio de información previa previsto en el artículo 134 que al menos recoja aquellos contratos que quedarán sujetos a una regulación armonizada".

${ }^{6}$ MEILÁN GIL, J.L., "Unidad del contrato público e interés general: itinerario de una investigación", Revista General de Derecho Administrativo, nº 48, Iustel, mayo 2018.
} 
1) Decreto $923 / 1965$, de 8 de abril, por el que se aprueba el texto articulado de la Ley de Contratos del Estado.

Es interesante la alusión que efectúa el Art.20 relativa a que la Administración debe hacer sus actuaciones preparatorias con la antelación precisa a fin de que estén ultimadas en la fecha prevista para la celebración del contrato y consiguiente iniciación de los trabajos con arreglo a los planes o programas correspondientes ${ }^{7}$.

2) Ley 13/1995, de 18 de mayo, de Contratos de las Administraciones Públicas.

Por una parte, recoge la necesidad de que la financiación se ajuste al ritmo de ejecución, de acuerdo con la programación de las anualidades (Art.14) 8 y, por otra parte, recoge, de acuerdo con la Directiva 2004/18, vigente en aquel momento, el anuncio indicativo (Arts.135, 178 y 204) ${ }^{9}$, aunque se limitaba a aquellos anuncios que superaran un determinado umbral.

\footnotetext{
${ }^{7}$ Art.20 del Decreto 923/1965, de 8 de abril, por el que se aprueba el texto articulado de la Ley de Contratos del Estado:

"A todo contrato de obras precederán las siguientes actuaciones administrativas:

1. Elaboración y aprobación del proyecto.

2. Redacción y aprobación del pliego de cláusulas administrativas particulares.

3. Tramitación del expediente de contratación.

La Administración realizará las actuaciones preparatorias con la antelación precisa a fin de que estén ultimadas en la fecha prevista para la celebración del contrato y consiguiente iniciación de los trabajos con arreglo a los planes o programas correspondientes".

${ }^{8}$ Art.14 de la Ley 13/1995 (Precio de los contratos):

“(...) 4. La financiación de los contratos por la Administración se ajustará al ritmo requerido en la ejecución de la prestación, debiendo adoptarse a este fin por el órgano de contratación las medidas que sean necesarias al tiempo de la programación de las anualidades y durante el período de ejecución".

${ }^{9}$ Art.135 de la Ley 13/1995 (Requisitos de publicidad):

"1. En cada ejercicio presupuestario, los órganos de contratación darán a conocer, mediante un anuncio indicativo, las características básicas de los contratos de obras que tengan proyectado celebrar en los próximos doce meses, cualquiera que sea el procedimiento de adjudicación que apliquen y cuyo importe, con exclusión del Impuesto sobre el Valor Añadido, sea igual o superior a 681.655.208 pesetas.

Este anuncio se enviará lo antes posible a partir de su programación a la Oficina de Publicaciones Oficiales de las Comunidades Europeas y, para que surta el efecto de reducción de plazos previsto en los artículos 137 y 138, deberá haberse publicado en el plazo comprendido entre cuarenta días y doce meses de antelación".
}

Art.178 de la Ley 13/1995 (Supuestos de publicidad):

"1. Los órganos de contratación darán a conocer, mediante un anuncio indicativo, los contratos totales por grupos de productos cuyo importe, con exclusión del Impuesto sobre el Valor Añadido, sea igual o superior a 102.248.281 pesetas, y que tengan previsto celebrar durante los doce meses siguientes.

Este anuncio se enviará lo antes posible, después del comienzo de cada ejercicio presupuestario, a la Oficina de Publicaciones Oficiales de las Comunidades Europeas y, para que surta el efecto de reducción de plazos previsto en los artículos 179 y 180.2, deberá haberse publicado en el plazo comprendido entre cuarenta días y doce meses de antelación".

Art.204 de la Ley 13/1995 (Supuestos de publicidad):

"1. Los órganos de contratación darán a conocer, mediante un anuncio indicativo, los contratos que tengan proyectado celebrar durante los doce meses siguientes en cada una de las categorías 1 a 16 de las enumeradas en el artículo 207, siempre que su importe, con exclusión del Impuesto sobre el Valor Añadido, sea igual o superior a 102.248.281 pesetas. Este anuncio se enviará lo antes posible. después del comienzo de cada ejercicio presupuestario. a la Oficina de Publicaciones Oficiales de las Comunidades Europeas y, para que surta el efecto de reducción de plazos previsto en los apartados 1 y 3 del artículo 208, deberá haberse publicado en el plazo comprendido entre cuarenta días y doce meses de antelación". 
3) Texto Refundido de la Ley de Contratos de las Administraciones Públicas, de 16 de junio, aprobado por Real Decreto Legislativo 2/2000 (TRLCAP).

Por una parte, recoge la necesidad de que la financiación se ajuste al ritmo de ejecución, de acuerdo con la programación de las anualidades (Art.14) ${ }^{10}$, siguiendo la línea de la Ley 13/1995 y, por otra parte, recoge, de acuerdo con la Directiva 2004/18, vigente en aquel momento, el anuncio indicativo (Arts.135, 177 y 203), aunque se limitaba a aquellos anuncios que superaran un determinado umbral ${ }^{11}$.

4) Real Decreto 1098/2001, de 12 de octubre, por el que se aprueba el Reglamento general de la Ley de Contratos de las Administraciones Públicas.

En este Reglamento, en su Art. $7^{12}$ se contempla la posibilidad de atribuir a las Juntas de Contratación las funciones de programación y estudio de las necesidades de los contratos a celebrar.

\footnotetext{
${ }^{10}$ Art.14 del TRLCAP (Precio de los contratos):

“(...) 3. La financiación de los contratos por la Administración se ajustará al ritmo requerido en la ejecución de la prestación, debiendo adoptarse a este fin por el órgano de contratación las medidas que sean necesarias al tiempo de la programación de las anualidades y durante el período de ejecución".

${ }^{11}$ Art.135 del TRLCAP (Supuestos de publicidad):

"1. En cada ejercicio presupuestario, los órganos de contratación darán a conocer, mediante un anuncio indicativo, las características básicas de los contratos de obras que tengan proyectado celebrar en los próximos doce meses, cualquiera que sea el procedimiento de adjudicación que apliquen y cuyo importe, con exclusión del Impuesto sobre el Valor Añadido, sea igual o superior a 891.521 .645 pesetas
} (5.358.153 euros, equivalentes a 5.000.000 derechos especiales de giro).

Este anuncio se enviará lo antes posible a partir de su programación a la Oficina de Publicaciones Oficiales de las Comunidades Europeas y, para que surta el efecto de reducción de plazos previsto en los artículos 137 y 138, deberá haberse enviado a la citada Oficina con una antelación mínima de cincuenta y dos días y máxima de doce meses, a partir de la fecha del envío del anuncio del contrato al "Diario Ofícial de las Comunidades Europeas"".

Art.177 del TRLCSP (Supuestos de publicidad):

"1. Los órganos de contratación darán a conocer, mediante un anuncio indicativo, los contratos totales por grupos de productos cuyo importe, con exclusión del Impuesto sobre el Valor Añadido, sea igual o superior a 124.789 .500 pesetas (750.000 euros) y que tengan previsto celebrar durante los doce meses siguientes.

Este anuncio se enviará lo antes posible a partir de su programación a la Oficina de Publicaciones Oficiales de las Comunidades Europeas y, para que surta el efecto de reducción de plazos previsto en los artículos 178 y 179, deberá haberse enviado a la citada Oficina con una antelación mínima de cincuenta y dos días y máxima de doce meses, a partir de la fecha del envío del anuncio del contrato al "Diario Oficial de las Comunidades Europeas"".

Art.203 del TRLCSP (Supuestos de publicidad):

"1. Los órganos de contratación darán a conocer, mediante un anuncio indicativo, los contratos que tengan proyectado celebrar durante los doce meses siguientes en cada una de las categorías 1 a 16 de las enumeradas en el artículo 206, siempre que su importe, con exclusión del Impuesto sobre el Valor Añadido, sea igual o superior a 124.789 .500 pesetas (750.000 euros).

Este anuncio se enviará lo antes posible a partir de su programación a la Oficina de Publicaciones Oficiales de las Comunidades Europeas y, para que surta el efecto de reducción de plazos previsto en el artículo 207, apartados 1 y 3 , deberá haberse enviado a la citada Oficina con una antelación mínima de cincuenta y dos días y máxima de doce meses a partir de la fecha del envío del anuncio del contrato al "Diario Oficial de las Comunidades Europeas"”.

${ }^{12}$ Art.7 del Real Decreto 1098/2001, de 12 de octubre, por el que se aprueba el Reglamento general de la Ley de Contratos de las Administraciones Públicas (Funciones de las Juntas de Contratación):

"Además de las funciones señaladas en el artículo 12.4 de la Ley, el Ministro podrá atribuir a las Juntas de Contratación las funciones de programación y estudio de las necesidades de contratos a celebrar y cualesquiera otras que estén relacionadas con la actividad contractual de la Administración del Estado en 
5) Ley 30/2007, de 30 de octubre, de Contratos del Sector Público.

En su Art. $42^{13}$ se refiere a la posibilidad de publicar en el Perfil de contratante las contrataciones programadas, pero con carácter voluntario.

También regula el anuncio previo en su Art. $125^{14}$ y atribuye funciones de programación de determinados contratos a TRAGSA ${ }^{15}$.

el ámbito de las competencias del Ministerio. En el desarrollo de esta actividad no será necesario que formen parte de la Junta de Contratación el asesor jurídico y el interventor".

${ }^{13}$ Art.42 de la Ley 30/2007 (Perfil de contratante):

"2. El perfil de contratante podrá incluir cualesquiera datos e informaciones referentes a la actividad contractual del órgano de contratación, tales como los anuncios de información previa contemplados en el artículo 125, las licitaciones abiertas o en curso y la documentación relativa a las mismas, las contrataciones programadas, los contratos adjudicados, los procedimientos anulados, y cualquier otra información útil de tipo general, como puntos de contacto y medios de comunicación que pueden utilizarse para relacionarse con el órgano de contratación. En todo caso deberá publicarse en el perfil de contratante la adjudicación de los contratos".

${ }^{14}$ Art.125 de la Ley 30/2007 (Anuncio previo):

"1. Los órganos de contratación podrán publicar un anuncio de información previa con el fin de dar a conocer, en relación con los contratos de obras, suministros y servicios que tengan proyectado adjudicar en los doce meses siguientes, los siguientes datos:

a) en el caso de los contratos de obras, las características esenciales de aquellos cuyo valor estimado sea igual o superior a 5.278 .000 euros.

b) En el caso de los contratos de suministro, su valor total estimado, desglosado por grupos de productos referidos a partidas del «Vocabulario Común de los Contratos Públicos» (CPV), cuando ese valor total sea igual o superior a 750.000 euros.

c) En el caso de los contratos de servicios, el valor total estimado para cada categoría de las comprendidas en los números 1 a 16 del anexo II, cuando ese valor total sea igual o superior a 750.000 euros.

2. Los anuncios se publicarán en el «Diario Oficial de la Unión Europea» o en el perfil de contratante del órgano de contratación a que se refiere el artículo 42.

En el caso de que la publicación vaya a efectuarse en el perfil de contratante del órgano de contratación, éste deberá comunicarlo previamente a la Comisión Europea y al «Boletín Oficial del Estado» por medios electrónicos, con arreglo al formato y a las modalidades de transmisión que se establezcan. En el anuncio previo se indicará la fecha en que se haya enviado esta comunicación.

3. Los anuncios se enviarán a la Oficina de Publicaciones Oficiales de las Comunidades Europeas o se publicarán en el perfil de contratante lo antes posible, una vez tomada la decisión por la que se autorice el programa en el que se contemple la celebración de los correspondientes contratos, en el caso de los de obras, o una vez iniciado el ejercicio presupuestario, en los restantes.

4. La publicación del anuncio previo cumpliendo con las condiciones establecidas en los artículos 143.1 y 151.1 permitirá reducir los plazos para la presentación de proposiciones en los procedimientos abiertos y restringidos en la forma que en esos preceptos se determina".

15 Disposición adicional trigésima de la Ley 30/2007 (Régimen jurídico de la «Empresa de Transformación Agraria, Sociedad Anónima» (TRAGSA), y de sus filiales):

“(...) 4. Las sociedades del grupo TRAGSA prestarán, por encargo de los poderes adjudicadores de los que son medios propios instrumentales, las siguientes funciones: (...)

g) La planificación, organización, investigación, desarrollo, innovación, gestión, administración y supervisión de cualquier tipo de servicios ganaderos, veterinarios, de seguridad y sanidad animal y alimentaria.

h) La recogida, transporte, almacenamiento, transformación, valorización, gestión y eliminación de productos, subproductos y residuos de origen animal, vegetal y mineral.

i) La realización de tareas o actividades complementarias o accesorias a las citadas anteriormente.

Las sociedades del grupo TRAGSA también estarán obligadas a satisfacer las necesidades de los poderes adjudicadores de los que son medios propios instrumentales en la consecución de sus objetivos de interés público mediante la realización, por encargo de los mismos, de la planificación, organización, investigación, desarrollo, innovación, gestión, administración y supervisión de cualquier tipo de asistencias y servicios técnicos en los ámbitos de actuación señalados en el apartado anterior, o mediante 
6) Real Decreto Legislativo 3/2011, de 14 de noviembre, por el que se aprueba el texto refundido de la Ley de Contratos del Sector Público (TRLCSP).

En su Art.53 ${ }^{16}$ recoge la posibilidad de publicar en el Perfil de contratante las contrataciones programadas, pero al igual que la Ley 30/2007, con carácter voluntario.

También regula el anuncio previo en su Art. $141^{17}$ y de igual modo atribuye funciones de programación de determinados contratos a TRAGSA ${ }^{18}$.

la adaptación y aplicación de la experiencia y conocimientos desarrollados en dichos ámbitos a otros sectores de la actividad administrativa".

${ }^{16}$ Art.53 del TRLCSP (Perfil de contratante):

“(...) 2. El perfil de contratante podrá incluir cualesquiera datos e informaciones referentes a la actividad contractual del órgano de contratación, tales como los anuncios de información previa contemplados en el artículo 141, las licitaciones abiertas o en curso y la documentación relativa a las mismas, las contrataciones programadas, los contratos adjudicados, los procedimientos anulados, y cualquier otra información útil de tipo general, como puntos de contacto y medios de comunicación que pueden utilizarse para relacionarse con el órgano de contratación. En todo caso deberá publicarse en el perfil de contratante la adjudicación de los contratos".

${ }^{17}$ Art.141 del TRLCSP (Anuncio previo):

"1. Los órganos de contratación podrán publicar un anuncio de información previa con el fin de dar a conocer, en relación con los contratos de obras, suministros y servicios que tengan proyectado adjudicar en los doce meses siguientes, los siguientes datos:

a) En el caso de los contratos de obras, las características esenciales de aquellos cuyo valor estimado sea igual o superior a 4.845 .000 euros.

b) En el caso de los contratos de suministro, su valor total estimado, desglosado por grupos de productos referidos a partidas del «Vocabulario Común de los Contratos Públicos» (CPV), cuando ese valor total sea igual o superior a 750.000 euros.

c) En el caso de los contratos de servicios, el valor total estimado para cada categoría de las comprendidas en los números 1 a 16 del anexo II, cuando ese valor total sea igual o superior a 750.000 euros.

2. Los anuncios se publicarán en el «Diario Oficial de la Unión Europea» o en el perfil de contratante del órgano de contratación a que se refiere el artículo 53.

En el caso de que la publicación vaya a efectuarse en el perfil de contratante del órgano de contratación, éste deberá comunicarlo previamente a la Comisión Europea y al «Boletín Oficial del Estado» por medios electrónicos, con arreglo al formato y a las modalidades de transmisión que se establezcan. En el anuncio previo se indicará la fecha en que se haya enviado esta comunicación.

3. Los anuncios se enviarán a la Oficina de Publicaciones Oficiales de las Comunidades Europeas o se publicarán en el perfil de contratante lo antes posible, una vez tomada la decisión por la que se autorice el programa en el que se contemple la celebración de los correspondientes contratos, en el caso de los de obras, o una vez iniciado el ejercicio presupuestario, en los restantes.

4. La publicación del anuncio previo cumpliendo con las condiciones establecidas en los artículos 159.1 y 167.1 permitirá reducir los plazos para la presentación de proposiciones en los procedimientos abiertos y restringidos en la forma que en esos preceptos se determina".

18 Disposición adicional vigésima quinta del TRLCSP (Régimen jurídico de la «Empresa de Transformación Agraria, Sociedad Anónima» (TRAGSA), y de sus filiales):

"4. Las sociedades del grupo TRAGSA prestarán, por encargo de los poderes adjudicadores de los que son medios propios instrumentales, las siguientes funciones: (...)

g) La planificación, organización, investigación, desarrollo, innovación, gestión, administración y supervisión de cualquier tipo de servicios ganaderos, veterinarios, de seguridad y sanidad animal y alimentaria.

h) La recogida, transporte, almacenamiento, transformación, valorización, gestión y eliminación de productos, subproductos y residuos de origen animal, vegetal y mineral.

i) La realización de tareas o actividades complementarias o accesorias a las citadas anteriormente.

Las sociedades del grupo TRAGSA también estarán obligadas a satisfacer las necesidades de los poderes adjudicadores de los que son medios propios instrumentales en la consecución de sus objetivos de interés público mediante la realización, por encargo de los mismos, de la planificación, organización, investigación, desarrollo, innovación, gestión, administración y supervisión de cualquier tipo de 
A su vez, en alguna Instrucción interna de contratación se han recogido previsiones en relación con la fase de planificación de las contrataciones ${ }^{19}$.

\section{LA PLANIFICACIÓN EN LOS INFORMES DE LOS CONSEJOS CONSULTIVOS Y JUNTAS CONSULTIVAS DE CONTRATACIÓN}

\subsection{PLANIFICACIÓN EN EL ÁMBITO SANITARIO}

Para abordar esta cuestión, resulta de gran relevancia el Dictamen 128/2016, de 21 de abril, del Consejo Consultivo de Canarias, Sección primera, que dispone lo siguiente:

"Por ello, una vez más, se debe reiterar a la Administración sanitaria la improcedencia de tal actuar, que podría evitarse si se hiciese una correcta planificación de su actividad y de la gestión contractual, con total respeto a los principios inspiradores de la contratación pública (publicidad y transparencia de los procedimientos y no discriminación e igualdad de trato entre los licitadores), sin duda alguna contribuiría a garantizar la utilización eficiente de los fondos públicos, principios consagrados en el art. 1 TRLCSP.

Ciertamente, una vez determinadas por la Administración sanitaria las necesidades que deben cubrirse -que son previsibles e incluso cuantificables- y concretado el alcance, tanto material como temporal, del objeto de los contratos que se requieren para satisfacerlas, una correcta planificación de las necesidades de contratación permitiría plantear diferentes opciones para cubrirlas (entre ellas, las señaladas en el art. 9.3 TRLCSP), así como ahorrar en los gastos de gestión de la contratación por una posible mejora de precios derivada no sólo por la agregación de demanda, aprovechando las economías de escala, sino también por la mayor concurrencia que permite una contratación abierta y competitiva.

Todo ello ha sido incumplido por la Administración sanitaria tal y como ha quedado patente en la totalidad de los supuestos dictaminados por este Consejo Consultivo en el pasado año, donde se ha procedido a contratar sin una correcta planificación previa que permita lograr una eficiencia y racionalidad en la utilización de los recursos públicos y con total desprecio a los principios reguladores de la contratación pública: transparencia, legalidad, seguridad jurídica, buena fe y confianza legítima. Este incorrecto proceder no ha sido corregido por la Administración sanitaria en el presente año se continúa remitiendo a este Consejo solicitudes de revisión de oficio de

asistencias y servicios técnicos en los ámbitos de actuación señalados en el apartado anterior, o mediante la adaptación y aplicación de la experiencia y conocimientos desarrollados en dichos ámbitos a otros sectores de la actividad administrativa".

${ }^{19}$ El Art.7 de la Instrucción Interna de Contratación de la Fundación estatal para la formación en el empleo, de 13 de febrero de 2013, indicaba que "La Fundación establecerá anualmente la planificación de los procesos de contratación que tiene previsto realizar en el ejercicio siguiente. Esta programación requerirá por parte de las direcciones proponentes un análisis interno de necesidades". 
expedientes de contratación que, en síntesis, presentan los mismos defectos que ya los ya dictaminados con anterioridad".

\subsection{PLANIFICACIÓN EN LA CONTRATACIÓN ESTRATEGICA}

En este ámbito destaca el Informe 14/2014, de 22 de julio, de la Junta Consultiva de Contratación Administrativa de la Generalitat de Catalunya (Comisión Permanente) ${ }^{20}$, que indica que:

"El punto de partida para la utilización de los mecanismos previstos en la normativa de contratos del sector público para cubrir las necesidades a que se refiere este informe, es la planificación de la contratación correcta la cual, además de permitir y contribuir al mejor respecto de los principios inspiradores de la contratación pública, contribuye también a garantizar la utilización eficiente de los fondos públicos -también prevista en el artículo 1 del TRLCSP.

Ciertamente, una vez determinadas por los entes, organismos o entidades del sector público las necesidades que deben cubrirse -que, en el supuesto objeto de consulta, son previsibles e incluso cuantificables- y concretado el alcance, tanto material como temporal, del objeto de los contratos que se requieren para satisfacerlas, planificar los contratos que hay que llevar a cabo permite poder plantear diferentes opciones para cubrirlas, así como también obtener ahorros en los gastos de gestión de la contratación; una posible mejora de precios por la agregación de demanda, aprovechando las economías de escala, pero también derivada de la mayor concurrencia que permite una contratación abierta y competitiva y la posibilidad de obtención de ofertas más ventajosas; incrementar la eficacia con la integración de la prestación en un único contrato; y optimizar la ejecución global del contrato, entre otra eficiencia. Así, simplemente el establecimiento de la duración de un contrato en un año prorrogable por otros periodos, en lugar de suscribir sucesivos contratos menores de duraciones inferiores, permite obtener estos beneficios, pudiendo concretar la duración total del contrato en función de cómo de satisfactorio haya sido el resultado en el plazo de duración inicial o de la evolución del mercado.

Asimismo, la correcta planificación previa de la contratación permite diseñar las licitaciones haciendo uso, por ejemplo, de la posibilidad prevista en el artículo 174.c del TRLCSP - que podría resultar idónea para alguno de los servicios que se mencionan en la petición de informe-, en la cual se conjugan tanto la simplificación y agilización del procedimiento de contratación, como el respeto total a la normativa y a los principios rectores de la contratación pública, al establecer que pueden adjudicarse por procedimiento negociado los servicios que consistan en la repetición de otros de similares adjudicados por procedimiento abierto o restringido al mismo contratista siempre que, entre otros requisitos, esta posibilidad esté indicada en el anuncio de

\footnotetext{
${ }^{20}$ Asunto: Contratación de prestaciones para cubrir necesidades de carácter recurrente o periódico. La contratación menor y la prohibición de fraccionamiento del objeto de los contratos del sector público.
} 
licitación del contrato inicial y el importe de los nuevos servicios se haya computado al fijar la cuantía total del contrato.

Asimismo, la correcta planificación previa también puede permitir diseñar la adquisición de suministros - tales como los que se mencionan en el escrito de petición de informe- mediante algún sistema de racionalización de la contratación, especialmente mediante el establecimiento de un acuerdo marco, con una o con diversas empresas, o la suscripción de un contrato de suministros en que la empresa contratista se obligue a entregar bienes de forma sucesiva y por precio unitario sin que la cuantía total se defina con exactitud en el momento de suscribir el contrato -previsto en el artículo 9.3 del TRLCSP.

Adicionalmente, conviene señalar que una correcta planificación previa de la contratación del sector público permite también hacer posible una contratación pública estratégica, en los términos en que se configura en la nueva Directiva 2014/24/UE del Parlamento Europeo y del Consejo, de 26 de febrero de 2014, sobre contratación pública y por la que se deroga la Directiva 2004/18/CE7, la cual resulta inviable sin aquella planificación".

La Junta Consultiva de Aragón, en el Informe 3/2018, de 13 de febrero ${ }^{21}$, señala lo siguiente:

"Puede presumirse que el objetivo de la nueva regulación de los contratos menores es prevenir su utilización para la cobertura de necesidades periódicas o recurrentes, que podrían satisfacerse mediante otros procedimientos de contratación si la necesaria planificación fuese adecuada. Esto está en línea con los pronunciamientos de diversos órganos consultivos o de control externo que, como el Tribunal de Cuentas en su informe núm. 1151/2016, de 27 de abril de 2016, de fiscalización de la contratación menor celebrada por el Instituto Nacional de la Seguridad Social, ejercicio 2013, recalca que no pueden utilizarse los contratos menores para atender necesidades periódicas y previsibles. El carácter recurrente de la necesidad se plasmará en objetos de los contratos idénticos o al menos similares, por lo que tiene pleno sentido que los límites cuantitativos para evitar ese uso abusivo de la contratación menor se apliquen separadamente para cada tipo contractual.

(...) A juicio de esta Junta, en cuanto al periodo sobre el que debe aplicarse, el criterio de la anualidad presupuestaria conecta directamente tanto con la necesaria planificación contractual, que debe servir para determinar a priori si la contratación menor va servir para cubrir adecuadamente las necesidades previsibles, como con los controles financieros que realiza la Intervención”.

Por último, cabe mencionar el Informe 1/2018, de 20 de abril, de la Junta Consultiva de Contratación Administrativa de la Generalitat de Catalunya (Comisión Permanente) ${ }^{22}$, que postula que:

\footnotetext{
${ }^{21}$ Asunto: Incompatibilidad para la adjudicación de contratos menores.

${ }^{22}$ Asunto: Límites a la contratación menor en la Ley 9/2017, de 8 de noviembre, de Contratos del Sector Público.
} 
"Así, tratándose de contratos menores adecuados, por no corresponderse a fracciones de un contrato o no obedecer a la voluntad de cubrir necesidades recurrentes que procediera vehicular, con la debida planificación y programación previa, a través de otras figuras previstas en la LCSP -como los sistemas de racionalización de la compra, los contratos de obras o servicios que consisten en repetición, contratos de suministros y de servicios de prestación sucesiva-, el plus que añade esta nueva obligación es que dichos contratos menores adjudicados haciendo un uso adecuado de esta figura, se contraten con varios empresarios con capacidad y con la habilitación profesional que, en su caso, sea necesaria para realizar la prestación y no siempre con los mismos, tomando como topes máximos cuantitativos de este límite el de los valores estimados que como máximo pueden tener estos contratos. (...)

Por lo tanto, hay que entender que el apartado 3 del artículo 118 de la LCSP establece dos obligaciones diferentes y complementarias, una primera relativa al objeto de los contratos menores, y una segunda relativa a las empresas que tienen que ser contratistas, cada una de las mismas tiene su finalidad diferente y complementaria de la otra. La primera, evitar fraccionamiento y la falta de planificación necesaria para cubrir necesidades periódicas y recurrentes -en definitiva, evitar el fraccionamiento, tanto el directamente fraudulento como aquel que sea debido a una incorrecta planificación y mala praxis-; y la segunda, limitar la posibilidad de que los contratos menores, a pesar de estar debidamente calificados como tales por provenir de una necesidad real y no fraccionada o incorrectamente planificada, se adjudiquen repetidamente a las mismas empresas".

\section{LA PLANIFICACIÓN EN LOS INFORMES DEL TRIBUNAL DE CUENTAS}

\subsection{PLANIFICACIÓN DE LAS ENCOMIENDAS}

El Tribunal de Cuentas, en su Informe de fiscalización sobre la utilización de la encomienda de gestión, regulada en la legislación de contratación pública aplicable, por las entidades del sector público autonómico español durante el ejercicio 2013, señala que:

"en ninguna de las CC.AA. existe un instrumento de planificación referente a las encomiendas, ni con carácter general ni entre las que se realizan dentro del ámbito de una misma Consejería. De este modo, las entidades encomendantes no cuentan con una planificación específica, con criterios estratégicos predefinidos, que permitan determinar qué prestaciones van a ser externalizadas, mediante la utilización de la figura del contrato, y cuáles se van a llevar a cabo mediante la encomienda de gestión”. 


\subsection{PLANIFICACIÓN DE UN TRANVÍA}

El Pleno del Tribunal de Cuentas ha aprobado el "Informe de Fiscalización del desarrollo, mantenimiento y gestión del Tranvía de Jaén" (Madrid, 18 de diciembre de 2017), que postula que:

"En relación con la planificación del tranvía: No consta la existencia de antecedentes ni la realización de estudios previos, por parte de la Junta de Andalucía ni del Ayuntamiento de Jaén, dirigidos a valorar la posible implantación en el municipio de Jaén de un tranvía. Tampoco consta que se realizaran informes en los que se comparara el transporte tranviario con otros medios alternativos con distinta incidencia, su viabilidad económico-financiera y el impacto en la Hacienda pública. Ello pone de manifiesto que no se llevó a cabo planificación alguna para el desarrollo de esta iniciativa".

\subsection{PRESTACIONES REITERADAS}

El Pleno del Tribunal de Cuentas en su "Informe de fiscalización de la contratación menor celebrada por el Instituto de Mayores y Servicios Sociales, ejercicios 2014 y 2015 " ha puesto de manifiesto que "a la vista del carácter reiterado y previsible de los servicios, de la similitud de las prestaciones, así como del fin único de las diversas contrataciones, habría sido precisa la realización de una planificación más racional de las necesidades y de las actuaciones para cubrirlas; de modo que, en lugar de proceder a la celebración de distintos contratos menores, se hubiera efectuado una contratación única por el importe conjunto de las prestaciones, a través del procedimiento establecido para cada caso, lo que, además, hubiera contribuido a dotar de una mayor publicidad y concurrencia a la contratación”.

\section{LA PLANIFICACION EN LAS DIRECTIVAS DE CONTRATOS}

\section{A. DIRECTIVAS HISTÓRICAS:}

\section{A.1 Directiva 93/37/CEE del Consejo, de 14 de junio de 1993, sobre coordinación de los procedimientos de adjudicación de los contratos públicos de obras}

Regula dos aspectos relacionados con la planificación, en primer lugar, en relación con la planificación de las obras relativas a proyecto y ejecución de viviendas sociales ${ }^{23}, y$, en segundo lugar, sobre los anuncios indicativos ${ }^{24}$.

\footnotetext{
${ }^{23}$ Art.9 de la Directiva 93/37/CEE:

"En el caso de los contratos relativos al proyecto y ejecución de obra para la construcción de un conjunto de viviendas sociales en los que, debido a la importancia, la complejidad y la duración estimada de las
} 


\section{A.2 Directiva 2004/17/CE del Parlamento Europeo y del Consejo de 31 de marzo de 2004 sobre la coordinación de los procedimientos de adjudicación de contratos en los sectores del agua, de la energía, de los transportes y de los servicios postales}

El Anexo XX.2 (Publicación de información complementaria o adicional) alude a la posibilidad de que el perfil de comprador incluya las compras programadas, señalando que:

“a) Se alentará a las entidades adjudicadoras a que publiquen en Internet la totalidad del pliego de condiciones y de la documentación complementaria.

b) El perfil de comprador puede incluir anuncios periódicos indicativos, contemplados en el apartado 1 del artículo 41, información sobre las convocatorias en curso, las compras programadas, los contratos adjudicados, los procedimientos anulados y cualquier otra información útil de tipo general como, por ejemplo, puntos de contacto, números de teléfono y de fax, dirección postal y dirección electrónica".

\section{A.3 Directiva 2004/18/CE del Parlamento Europeo y del Consejo de 31 de marzo de 2004, sobre coordinación de los procedimientos de adjudicación de los contratos públicos de obras, de suministro y de servicios}

Regula, al igual que a Directiva 93/37, dos aspectos relacionados con la planificación, en primer lugar, en relación con la planificación de las obras relativas a proyecto y ejecución de viviendas sociales ${ }^{25}$ y, en segundo lugar, sobre los anuncios indicativos ${ }^{26}$.

obras correspondientes, la planificación deba establecerse desde el principio en el seno de un equipo en el que colaboren estrechamente los delegados de los poderes adjudicadores, los expertos y el contratista que tendrá a su cargo la ejecución de las obras, podrá recurrirse a un procedimiento especial de adjudicación destinado a elegir el contratista más adecuado para ser integrado en dicho equipo.

En particular, los poderes adjudicadores harán figurar en el anuncio de contrato una descripción de las obras tan exacta como sea posible, que permita a los contratistas interesados una apreciación válida del proyecto a ejecutar. Por otra parte, los poderes adjudicadores mencionarán en dicho anuncio de contrato las condiciones personales, técnicas y financieras que deberán reunir los candidatos, de acuerdo con los artículos 24 a 29.

Cuando recurran a este procedimiento, los poderes adjudicadores aplicarán las reglas comunes de publicidad referentes al procedimiento restringido, y aquellas relativas a los criterios de selección cualitativa".

${ }^{24}$ Art.11 (apartados 1 y 7) de la Directiva 93/37/CEE:

"1. Los poderes adjudicadores darán a conocer, mediante un anuncio indicativo, las características básicas de los contratos de obras que tengan proyectado adjudicar, cuyos importes sean iguales o superiores al umbral indicado en el apartado 1 del artículo 6".

$(\ldots)$

7: (...) El anuncio contemplado en el apartado 1 se enviará lo antes posible después de la adopción de la decisión por la que se autoriza el programa en el que se inscriben los contratos de obras que los poderes adjudicadores proyecten adjudicar”.

25 Art.34 de la Directiva 2004/18/CE (Contratos públicos de obras: normas particulares sobre construcción de viviendas sociales):

"En el caso de los contratos públicos relativos al proyecto y ejecución de obras para la construcción de un conjunto de viviendas sociales en los que, debido a la importancia, la complejidad y la duración estimada de las obras correspondientes, la planificación deba establecerse desde el principio por un equipo en el que colaboren estrechamente los delegados de los poderes adjudicadores, los expertos y el contratista que 


\section{B. DIRECTIVAS VIGENTES:}

\section{B.1 Directiva 2014/24/UE del Parlamento Europeo y del Consejo, de 26 de febrero de 2014, sobre contratación pública y por la que se deroga la Directiva 2004/18/CE}

Cabe mencionar el Considerando 121, que establece lo siguiente:

“(...) Una mejor orientación, información y asistencia a los poderes adjudicadores y los agentes económicos podría también contribuir en gran medida a hacer más eficiente la contratación pública gracias a mejores conocimientos, a una mayor seguridad jurídica y a la profesionalización de las prácticas de contratación. Dicha orientación debería hacerse accesible a los poderes adjudicadores y a los operadores económicos siempre que parezca necesario mejorar la aplicación de las normas. La orientación que se ha de ofrecer podría cubrir todos los aspectos pertinentes de la contratación pública, como la planificación de la adquisición, los procedimientos, la elección de técnicas e instrumentos y las buenas prácticas para tramitar los procedimientos. (...)".

En este sentido la consulta de mercado puede ser un instrumento adecuado para el proceso de planificación. Así, el Art.40, en su párrafo segundo señala que:

"Para ello, los poderes adjudicadores podrán, por ejemplo, solicitar o aceptar el asesoramiento de expertos o autoridades independientes o de participantes en el mercado, que podrá utilizarse en la planificación y el desarrollo del procedimiento de contratación, siempre que dicho asesoramiento no tenga por efecto falsear la competencia y no dé lugar a vulneraciones de los principios de no discriminación y transparencia".

También cabe aludir al Art.83, que dispone que:

“(...) 4. Los Estados miembros se asegurarán:

tenga a su cargo la ejecución de las obras, se podrá recurrir a un procedimiento especial de adjudicación destinado a elegir el contratista más adecuado para ser integrado en dicho equipo. (...)”.

${ }^{26}$ Art.35 de la Directiva 2004/18/CE(Anuncios):

“1. Los poderes adjudicadores se servirán de un anuncio de información previa, publicado por la Comisión o por ellos mismos sobre su "perfil de comprador", tal como se define en la letra b) del punto 2 del anexo VIII, para dar a conocer: (...)

c) en el caso de las obras, las características esenciales de los contratos o de los acuerdos marco que prevean adjudicar y cuyos valores estimados sean iguales o superiores al umbral indicado en el artículo 7, teniendo en cuenta el artículo 9.

Los anuncios a que se refieren las letras a) y b) se enviarán a la Comisión o se publicarán en el perfil de comprador lo antes posible una vez iniciado el ejercicio presupuestario.

El anuncio a que se refiere la letra c) se enviará a la Comisión o se publicará en el perfil de comprador lo antes posible una vez tomada la decisión por la que se autorice el programa en el que figuren los contratos de obras o los acuerdos marco que los poderes adjudicadores proyecten adjudicar. (...)”.

Anexo VIII.2 de la Directiva 2004/18/CE (Publicación de información complementaria o adicional):

“a) Se anima a los poderes adjudicadores a publicar en Internet la totalidad del pliego de condiciones y de la documentación complementaria.

b) El perfil de comprador puede incluir anuncios de información previa, contemplados en el párrafo primero del apartado 1 del artículo 35, información sobre las licitaciones en curso, las compras programadas, los contratos adjudicados, los procedimientos anulados y cualquier otra información útil de tipo general, como, por ejemplo, un punto de contacto, los números de teléfono y de telefax, una dirección postal y una dirección electrónica”. 
a) de que se pueda acceder gratuitamente a información y orientaciones sobre la interpretación y aplicación de la legislación de la Unión en materia de contratación pública, con el fin de ayudar a los poderes adjudicadores y los operadores económicos, en especial las PYME, a aplicar correctamente las normas sobre contratación pública de la Unión, y

b) de que se facilite apoyo a los poderes adjudicadores para ayudarles a planificar y llevar a cabo procedimientos de contratación”.

Por último, resulta procedente mencionar el Anexo VIII.2 (Publicación de información complementaria o adicional), que postula lo siguiente:

“a) Salvo que se disponga lo contrario en los párrafos segundo y tercero del artículo 53, apartado 1, los poderes adjudicadores publicarán los pliegos de la contratación en su totalidad en internet.

b) El perfil de comprador podrá incluir anuncios de información previa contemplados en el artículo 48, apartado 1, información sobre las convocatorias en curso, las compras programadas, los contratos celebrados, los procedimientos anulados y cualquier otra información útil de tipo general como, por ejemplo, puntos de contacto, números de teléfono y de fax, dirección postal y dirección electrónica. El perfil de comprador podrá incluir también anuncios de información previa que sirvan de convocatoria de licitación y que se publicarán a escala nacional de conformidad con el artículo 52”.

\section{B.2 Directiva 2014/23/UE del Parlamento Europeo y del Consejo de 26 de febrero de 2014, relativa a la adjudicación de contratos de concesión}

No hay referencias.

\section{B.3 Directiva 2014/25/UE Del Parlamento Europeo y del Consejo de 26 de febrero de 2014, relativa a la contratación por entidades que operan en los sectores del agua, la energía, los transportes y los servicios postales y por la que se deroga la Directiva 2004/17/CE}

Cabe aludir en primer lugar al Considerando 127, que postula que:

“(...) Una mejor orientación, información y apoyo a las entidades adjudicadoras y los agentes económicos podría también contribuir en gran medida a hacer más eficiente la contratación pública gracias a la posesión de mejores conocimientos y de una mayor certidumbre jurídica y a la profesionalización de las prácticas de contratación. Dicha orientación debería hacerse accesible a las entidades adjudicadoras y a los operadores económicos siempre que parezca necesario mejorar la correcta aplicación de las normas. La orientación que se ha de ofrecer podría cubrir todos los aspectos pertinentes de la contratación pública, como la planificación de la adquisición, los procedimientos, la elección de técnicas e instrumentos y las prácticas adecuadas para ejecutar los procedimientos. (...)". 
Por lo que respecta a su articulado, destacan los siguientes preceptos:

- El Art.58:

“(...) Para ello, las entidades adjudicadoras podrán, por ejemplo, solicitar o aceptar el asesoramiento de expertos o autoridades independientes o de participantes en el mercado, que podrá utilizarse en la planificación y el desarrollo del procedimiento de contratación, siempre que dicho asesoramiento no tenga por efecto falsear la competencia y no dé lugar a infracciones de los principios de no discriminación y transparencia".

- El Art.99:

“(...) 4. Los Estados miembros se asegurarán:

a) de que se pueda acceder gratuitamente a información y orientaciones sobre la interpretación y aplicación del Derecho de la Unión en materia de contratación pública, con el fin de ayudar a los poderes adjudicadores y los operadores económicos, en especial las PYME, a aplicar correctamente las normas sobre contratación pública de la Unión, y

b) de que se facilite apoyo a los poderes adjudicadores para ayudarles a planificar y llevar a cabo procedimientos de contratación”.

Finalmente, también debemos aludir al Anexo IX.2 (Publicación de información complementaria o adicional), que indica lo siguiente:

“a) Salvo que se disponga otra cosa en el artículo 73, apartado 1, párrafos tercero y cuarto, las entidades adjudicadoras publicarán los pliegos de la contratación en su totalidad en internet.

b) El perfil de comprador podrá incluir los anuncios periódicos indicativos contemplados en el artículo 67, apartado 1, información sobre las convocatorias en curso, las compras programadas, los contratos celebrados, los procedimientos anulados y cualquier otra información útil de tipo general como, por ejemplo, puntos de contacto, números de teléfono y de fax, dirección postal y dirección electrónica. El perfil de comprador podrá incluir también anuncios periódicos indicativos que sirvan de convocatoria de licitación y que se publicarán a escala nacional de conformidad con el artículo 72". 
VII. LA PLANIFICACIÓN Y PROGRAMACIÓN EN LA LEY 9/2017, DE 8 DE NOVIEMBRE, DE CONTRATOS DEL SECTOR PÚBLICO, POR LA QUE SE TRANSPONEN AL ORDENAMIENTO JURÍDICO ESPAÑOL LAS DIRECTIVAS DEL PARLAMENTO EUROPEO Y DEL CONSEJO 2014/23/UE Y 2014/24/UE, DE 26 DE FEBRERO DE 2014 DE CONTRATOS DEL SECTOR PÚBLICO

\subsection{CONSIDERACIONES PREVIAS}

El Art. $28 \mathrm{LCSP}^{27}$ regula dos aspectos de la planificación:

A) La programación de la actividad contractual

B) El Plan de Contratación

Al respecto, Vega $M^{a}$ Arnáez Arce ${ }^{28}$ señala que "los planes contienen orientaciones, objetivos y directrices generales mientras que los programas concretan los medios que deben ponerse en práctica para realizar los objetivos fijados por los planes".

Sebastián Martín-Retortillo ${ }^{29}$ apunta que "Planificación y Plan -actividad e instrumentoson jurídicamente conceptos concurrentes, no son, sin embargo coincidentes. Se trata de una observación que hay que tener muy en cuenta: si todo Plan, en cuanto instituto jurídico, conlleva y establece siempre una determinada planificación, incluso cabe afirmar que es la forma más propia a través de la que se lleva a cabo, no es siempre cierta la proposición inversa. Se planifica a través de Planes: no sólo, sin embargo, por medio de ellos".

\subsection{PLAN DE CONTRATACIÓN ${ }^{30}$}

Todo Plan implica una labor previa de previsión y reflexión mediante la realización de los correspondientes estudios, tomas de datos y análisis previos, partiendo de la realidad actual y de la situación presente, donde se analicen las necesidades públicas a satisfacer, cuáles son los objetivos prioritarios, los fines y resultados que se pretenden, las distintas opciones, y determinando si la atención de las necesidades públicas se realizará con medios propios o a través de medios externos, utilizando las técnicas contractuales. También implica revisar cuáles son los aspectos a rectificar o modificar en los nuevos contratos, partiendo de la experiencia existente, completando o dando nueva redacción a determinadas cláusulas del pliego, así como mediante las

\footnotetext{
${ }^{27}$ Art.28 de la LCSP (Necesidad e idoneidad del contrato y eficiencia en la contratación):

“(...) 4. Las entidades del sector público programarán la actividad de contratación pública, que desarrollarán en un ejercicio presupuestario o períodos plurianuales y darán a conocer su plan de contratación anticipadamente mediante un anuncio de información previa previsto en el artículo 134 que al menos recoja aquellos contratos que quedarán sujetos a una regulación armonizada”.

28 ARNÁEZ ARCE, V. M., La potestad planificadora de las Administraciones Públicas, Editorial Gomylex, 2013, pág. 47.

${ }^{29}$ MARTÍN-RETORTILlO, S., Derecho administrativo económico, Tomo I, La Ley, 1988, pág. 333.
} 
correspondientes tomas de datos, recopilación de contratos existentes o vigentes, encuestas y petición de informes a los responsables o directores de los anteriores contratos para que expongan sus experiencias y sugerencias, orientadas desde perspectivas temporales hacia el futuro, desde principios de eficacia y eficiencia, y en especial desde una perspectiva de uso racional de los recursos públicos, evaluando los medios materiales, personales y económicos o financieros de los que se dispone, para concluir en una fundamentada y motivada toma de decisiones.

Para ello deberán definirse claramente las necesidades a satisfacer, que se concretarán en su objeto y en las prescripciones técnicas, recurriendo cuando sea necesario a las consultas preliminares de mercado, estudiando los costes directos e indirectos y velando que los precios incluyan los recogidos en los convenios colectivos, los anuncios previos...

Cuando como consecuencia de estos estudios se llegue a la conclusión de que la actividad se tiene que prestar a través de contrato, se deberán evaluar:

- las necesidades a satisfacer ${ }^{31}$,

- las autorizaciones, permisos o disponibilidad de terrenos (expropiaciones, traslados de postes, etc, en su caso) que se requieran, ya que una inadecuada planificación en esta materia puede dar lugar a retrasos injustificados e incluso a la resolución del contrato por falta de disponibilidad, con grave perjuicio para el interés público,

- su contenido,

- las prescripciones técnicas,

- el presupuesto del contrato y su financiación,

- los procedimientos de adjudicación,

- los criterios de selección y adjudicación, medidas para favorecer la concurrencia, igualdad y no discriminación.

- el ámbito temporal, plazos realistas ${ }^{32}$ de ejecución ${ }^{33}$ y posibles prorrogas, anualidades $^{34}$, presupuesto y financiación,

\footnotetext{
${ }^{31}$ Art.233 LCSP (Contenido de los proyectos y responsabilidad derivada de su elaboración):

"1. Los proyectos de obras deberán comprender, al menos:

a) Una memoria en la que se describa el objeto de las obras, que recogerá los antecedentes y situación previa a las mismas, las necesidades a satisfacer y la justificación de la solución adoptada, detallándose los factores de todo orden a tener en cuenta. (...)".

${ }^{32}$ El Tribunal Auditor de Austria, en sus recomendaciones para mejorar la Contratación Pública habla de que la planificación de las contrataciones debería contener objetivos realistas en cuanto a sus plazos de ejecución. Organización para la Cooperación y el Desarrollo Económico (OCDE), La integridad en la contratación Pública, Buenas prácticas de la A a la Z, Instituto Nacional de Administración Pública, Madrid, 2009, pág. 107.

${ }^{33}$ Art. 29 de la LCSP:

"1. La duración de los contratos del sector público deberá establecerse teniendo en cuenta la naturaleza de las prestaciones, las características de su financiación y la necesidad de someter periódicamente a concurrencia la realización de las mismas, sin perjuicio de las normas especiales aplicables a determinados contratos".
} 
- así como los gastos de mantenimiento ulteriores y el ciclo de vida ${ }^{35}$,

- aspectos sociales y medioambientales ${ }^{36}$ y condiciones especiales de ejecución,

- control de calidad,

- modificaciones del contrato, etc.

La ley no indica en qué fechas o con qué periodicidad se tiene que aprobar, sólo señala "anticipadamente", lo cual es demasiado inconcreto y ambiguo. Tampoco señala cuál debe ser el contenido mínimo del Plan, ¿se refiere a un mero listado con previsiones presupuestarias y plazos de ejecución?

La respuesta nos la da en parte la remisión al Art.134 $\operatorname{LCSP}^{37}$, pues este precepto se remite al Anexo III de la LCSP ${ }^{38}$.

\footnotetext{
${ }^{34}$ El Art.308.3 de la LCSP indica que la financiación y pago de los contratos de servicios que impliquen el desarrollo o mantenimiento de aplicaciones informáticas "se ajustará al ritmo requerido en la ejecución de los componentes de prestación requeridos, debiendo adoptarse a este fin por el responsable del contrato, las medidas que sean necesarias para la programación de las anualidades y durante el período de ejecución".

${ }^{35}$ Vid., entre otros, el Art.148 de la LCSP.

${ }^{36}$ Como antecedente: Orden PRE/116/2008, de 21 de enero, por la que se publica el Acuerdo de Consejo de Ministros por el que se aprueba el Plan de Contratación Pública Verde de la Administración General del Estado y sus Organismos Públicos, y las Entidades Gestoras de la Seguridad Social (BOE n²7, de 31 de enero de 2008).
}

${ }^{37}$ Art.134 de la LCSP (Anuncio de información previa):

"1. Los órganos de contratación podrán publicar un anuncio de información previa con el fin de dar a conocer aquellos contratos de obras, suministros o servicios que, estando sujetos a regulación armonizada, tengan proyectado adjudicar en el plazo a que se refiere el apartado 5 del presente artículo.

2. Los anuncios de información previa a que se refiere el apartado anterior se publicarán, con el contenido establecido en el Anexo III. A, a elección del órgano de contratación, en el «Diario Oficial de la Unión Europea» o en el perfil de contratante del órgano de contratación a que se refiere el artículo 63 que se encuentre alojado en la Plataforma de Contratación del Sector Público o servicio de información equivalente a nivel autonómico.

3. Los anuncios de información previa se enviarán a la Oficina de Publicaciones de la Unión Europea o, en su caso, se publicarán en el perfil de contratante, lo antes posible, una vez tomada la decisión por la que se autorice el programa en el que se contemple la celebración de los correspondientes contratos, en el caso de los de obras, o una vez iniciado el ejercicio presupuestario, en los restantes.

En cualquier caso, los poderes adjudicadores deberán poder demostrar la fecha de envío del anuncio de información previa.

La Oficina de Publicaciones de la Unión Europea confirmará al poder adjudicador la recepción del anuncio y la publicación de la información enviada, indicando la fecha de dicha publicación. Esta confirmación constituirá prueba de la publicación.

4. En el caso de que el anuncio de información previa se publique en el «Diario Oficial de la Unión Europea», no se publicará a nivel nacional antes de aquella publicación. No obstante, podrá en todo caso publicarse a nivel nacional si los poderes adjudicadores no han recibido notificación de su publicación a las cuarenta y ocho horas de la confirmación de la recepción del anuncio por parte de la Oficina de Publicaciones de la Unión Europea.

5. En el caso de que la publicación del anuncio de información previa a que se refiere el primer apartado se vaya a efectuar en el perfil de contratante del órgano de contratación, este último deberá enviar a la Oficina de Publicaciones de la Unión Europea el anuncio de la publicación en su perfil.

El anuncio de información previa no se publicará en el perfil de contratante antes de que se envíe a la Oficina de Publicaciones de la Unión Europea el anuncio de su publicación en la citada forma, e indicará la fecha de dicho envío. 
6. El periodo cubierto por el anuncio de información previa será de un máximo de 12 meses a contar desde la fecha de envío del citado anuncio a la Oficina de Publicaciones de la Unión Europea o, en su caso, a partir de la fecha de envío también a esta última, del anuncio de publicación en el perfil de contratante a que se refiere el apartado cuarto anterior.

Sin embargo, en el caso de los contratos de servicios que tengan por objeto alguno de los servicios especiales del Anexo IV, el anuncio de información previa podrá abarcar un plazo superior a 12 meses.

7. La publicación del anuncio previo a que se refiere el primer apartado de este artículo, cumpliendo con las condiciones establecidas en los apartados 2 y 3 del artículo 156 y en el apartado 1 del artículo 164 , permitirá reducir los plazos para la presentación de proposiciones en los procedimientos abiertos y restringidos en la forma que en esos preceptos se determina".

${ }^{38}$ Anexo III de la LCSP (Información que debe figurar en los anuncios):

“A) Información que debe figurar en los anuncios de publicación de un anuncio de información previa en un perfil de contratante, de información previa, de licitación, de formalización y de modificación de contratos de obras, suministros y servicios.

Sección 1. Información que debe figurar en los anuncios de la publicación de un anuncio de información previa en un perfil de contratante:

1. Nombre, número de identificación, dirección, incluido código NUTS, número de teléfono y de fax, y dirección electrónica y de internet del poder adjudicador y, en caso de ser diferente, del servicio del que pueda obtenerse información complementaria.

2. Tipo de poder adjudicador y principal actividad ejercida.

3. Cuando proceda, indicación de que el poder adjudicador es una central de compras, o de que se va a utilizar, o se puede utilizar, alguna otra forma de contratación conjunta.

4. Códigos CPV.

5. Dirección de internet del «perfil de contratante» (URL).

6. Fecha de envío del anuncio relativo a la publicación de un anuncio de información previa en el perfil de contratante.

Sección 2. Información que debe figurar en los anuncios de información previa cuando no proceda la aplicación de la sección 3 siguiente:

1. Nombre, número de identificación, dirección, incluido código NUTS, número de teléfono y de fax, y dirección electrónica y de internet del poder adjudicador y, en caso de ser diferente, del servicio del que pueda obtenerse información complementaria.

2. Dirección electrónica o de internet en la que estarán disponibles los pliegos de la contratación para un acceso libre, directo, completo y gratuito.

Cuando no se disponga de un acceso libre, directo, completo y gratuito por los motivos contemplados en el artículo 138, una indicación sobre el modo de acceso a los pliegos de la contratación.

3. Tipo de poder adjudicador y principal actividad ejercida.

4. Cuando proceda, indicación de que el poder adjudicador es una central de compras, o de que se va a utilizar, o se puede utilizar, alguna otra forma de contratación conjunta.

5. Códigos CPV cuando la concesión esté dividida en lotes, esta información se facilitará para cada lote.

6. Código NUTS del emplazamiento principal de las obras, en el caso de los contratos de obras, o código

NUTS del lugar principal de entrega o de ejecución en los contratos de suministro y de servicios. Cuando

la concesión esté dividida en lotes, esta información se facilitará para cada lote.

7. Breve descripción de la contratación: naturaleza y alcance de las obras, naturaleza y cantidad o valor de los suministros, naturaleza y alcance de los servicios.

8. Cuando este anuncio no se utilice como medio de convocatoria de licitación, las fechas estimadas para la publicación de uno o varios anuncios de licitación con respecto al contrato o los contratos a los que se refiera este anuncio de información previa.

9. Fecha de envío del anuncio.

10. Si procede, otras informaciones.

11. Indicación de si el ACP es aplicable al contrato.

Sección 3. Información que debe figurar en los anuncios de información previa de servicios especiales del Anexo IV:

1. Nombre, número de identificación (cuando esté previsto en la legislación nacional), dirección, incluido código NUTS, dirección electrónica y de internet del poder adjudicador.

2. Breve descripción del contrato de que se trate, incluidos el valor estimado total del contrato y los números de referencia a la nomenclatura $\mathrm{CPV}$.

3. En la medida en que ya se conozcan: 
La planificación debe ir encaminada a que se puedan atender en plazo las necesidades públicas, lo cual significa que todos los tramites de preparación, selección, adjudicación y ejecución se tienen que realizar con la antelación suficiente. La planificación es lo contrario de la imprevisión.

La planificación va intrínsecamente unida a la necesidad del contrato. Como señala Luis Jaime Rodríguez Fernández "la planificación y la programación son requisitos para una actuación eficaz, previsora y diligente por parte de las Administraciones Públicas ${ }^{40}$. Este principio debe ir vinculado a los principios de ejecución presupuestaria”.

\subsubsection{PUBLICIDAD DEL PLAN DE CONTRATACIÓN}

Debe hacerse mediante el anuncio de información previa previsto en el Art.134 de la LCSP (ya citado), que al menos recoja aquellos contratos que quedarán sujetos a una regulación armonizada.

Del análisis de este texto constatamos que aunque en el artículo se dice "darán a conocer", a continuación restringe esta obligatoriedad para los contratos sujetos a regulación armonizada.

Entendemos que esta publicidad debería exigirse para todo tipo de contratos, incluidos por tanto los no sujetos a regulación armonizada.

\subsection{QUÉ SE DEBE PROGRAMAR}

La ley habla de programar la "actividad de contratación pública", pero no concreta cuál es esa actividad de contratación pública, ni cómo debe hacerlo. Entendemos que en este caso son aplicables las técnicas organizativas propias de las políticas públicas y que debe hacerse en el marco del Plan de Contratación. Asimismo, consideramos que esa actividad de programación debe ser global y debe referirse a todo el ciclo de la contratación en sus diversas fases, es decir desde:

a) Código NUTS del emplazamiento principal de las obras, en el caso de las obras, o código NUTS del lugar principal de entrega o de ejecución en el caso de los suministros y los servicios;

b) Calendario de entrega de los bienes, la realización de las obras o la prestación de los servicios y duración del contrato;

c) Condiciones para la participación, y, en concreto:

Cuando proceda, indicación de si el contrato público está restringido a talleres protegidos o si se prevé que sea ejecutado únicamente en el marco de programas de empleo protegido,

Cuando proceda, indicar si con arreglo a disposiciones legales, reglamentarias o administrativas, se reserva la prestación del servicio a una determinada profesión;

d) Breve descripción de las características principales del procedimiento de adjudicación que se va a aplicar. (...)".

${ }^{39}$ RODRÍGUEZ FERNÁNDEZ, L.J., "Reflexiones sobre la contratación en el ordenamiento jurídico español a la luz de las nuevas Directivas europeas de Contratación y Anteproyecto de ley de contratos del sector público", en AAVV., Cuadernos de Mariñán.2016, IX Jornadas de Derecho Administrativo Iberoamericano "Contratación, Ordenación del Territorio y Buena Administración", Editorial Deputación Provincial da Coruña, 2018, pág. 168.

${ }^{40}$ Considerando 121 de la Directiva 2014/24/UE. 
1.- La preparación del contrato.

2.- El procedimiento de adjudicación, analizando cuál es el procedimiento más adecuado y cuáles son los criterios de solvencia y selección más adecuados que favorezcan la concurrencia, dentro del interés público.

3.- La fase de ejecución, concretando los derechos y obligaciones de las partes y en especial las formas de verificar el adecuado cumplimiento del contrato.

4.- La perspectiva temporal desde el punto de vista cualitativo como temporal.

\subsubsection{APLICACIONES ADECUADAS}

La Administración debe contar con los adecuados registros y aplicaciones informáticas que le permitan evaluar todas los datos e incidencias contractuales. Asimismo es fundamental que la aplicación informática, integrada en la programación y en el Plan de Contratación avise automáticamente o pueda consultarse con la suficiente antelación, al menos con 4 meses de antelación de cuándo finaliza un contrato y si es o no susceptible de prórroga, a fin de evitar perjuicios al interés público y poder siempre tramitar con tiempo suficiente las prórrogas o los nuevos contratos ${ }^{41}$.

En muchas ocasiones las Administraciones han acudido a la tramitación urgente para paliar la falta de previsión y planificación, circunstancias que ha señalado reiteradamente el Tribunal de Cuentas y Órganos equivalentes de las Comunidades Autónomas.

\subsection{2. ÁMBITO TEMPORAL}

La ley indica que puede referirse a un ejercicio presupuestario o periodos plurianuales, pero tampoco fija ningún tipo de pautas. De ahí que deja en manos de cada Administración o entidad el establecerlo. Al referirse a periodos plurianuales no señala cuál es el periodo que debe abarcar, y en esta situación habrá que tener en cuenta la Ley General Presupuestaria (Ley 47/2003, de 26 de noviembre, General Presupuestaria) y la Ley de Haciendas Locales (Texto refundido de la Ley reguladora de las Haciendas Locales, aprobado por Real Decreto Legislativo 2/2004, de 5 de marzo).

\section{LA DIVISIÓN EN LOTES COMO ESTUDIO A INCLUIR EN LA PROGRAMACIÓN DE LOS CONTRATOS}

El Art.1.3 de la LCSP incluye que "se facilitará el acceso a la contratación pública de las pequeñas y medianas empresas, así como de las empresas de economía social”.

\footnotetext{
${ }^{41}$ Vid. Art.75.2 de la Ley 39/2015, de 1 de octubre, del Procedimiento Administrativo Común de las Administraciones Públicas:

"Las aplicaciones y sistemas de información utilizados para la instrucción de los procedimientos deberán garantizar el control de los tiempos y plazos, la identificación de los órganos responsables y la tramitación ordenada de los expedientes, así como facilitar la simplificación y la publicidad de los procedimientos".
} 
Como un medio para hacer efectiva esta concurrencia está la división del contrato en lotes. En este sentido, el Art.99 LCSP señala que debe justificarse la no división del contrato en lotes ${ }^{42}$.

Por ello, los órganos de contratación deberán estudiar y planificar adecuadamente qué tipo de contratos deben dividirse en lotes para favorecer la concurrencia de las PYMES.

\section{LOS ASPECTOS SOCIALES Y MEDIOAMBIENTALES EN EL MARCO DE LA PLANIFICACIÓN DE LOS CONTRATOS}

La LCSP consagra el carácter transversal de los aspectos sociales y medioambientales en la contratación pública (Art.1.3), y por ello la planificación de los contratos debe tener en cuenta esta circunstancia, determinando las líneas estratégicas, ámbitos, sectores y actividades donde se recogerán los aspectos sociales y medioambientales, bien como requisitos de solvencia, criterios de adjudicación (Art.145), de desempate o de condiciones de ejecución (Art.202).

Por otra parte, la reserva de determinados contratos a Centros Especiales de Empleo de iniciativa social y a empresas de inserción hace necesario e imprescindible estudiar, analizar y planificar los contratos reservados a estas entidades, de conformidad con lo establecido en la Disposición Adicional Cuarta o reservarles determinados lotes (Art. 99.4).

\section{$X$. LAS CONSULTAS PRELIMINARES DE MERCADO COMO INSTRUMENTO PARA LA PLANIFICACIÓN DE LOS CONTRATOS}

Las consultas preliminares de mercado pueden ser un instrumento adecuado para planificar los contratos. En este sentido se manifiestan la Directiva 2014/24/UE $\left(\right.$ Art. $\left.40^{43}\right)$ y la LCSP (Art. $\left.115.2^{44}\right)$.

\footnotetext{
${ }^{42}$ Art.99.3 de la LCSP:

"Siempre que la naturaleza o el objeto del contrato lo permitan, deberá preverse la realización independiente de cada una de sus partes mediante su división en lotes, pudiéndose reservar lotes de conformidad con lo dispuesto en la disposición adicional cuarta.

No obstante lo anterior, el órgano de contratación podrá no dividir en lotes el objeto del contrato cuando existan motivos válidos, que deberán justificarse debidamente en el expediente, salvo en los casos de contratos de concesión de obras. (...)".

${ }^{43}$ Art.40 de la Directiva 2014/24/UE (Consultas preliminares del mercado):

"Antes de iniciar un procedimiento de contratación, los poderes adjudicadores podrán realizar consultas del mercado con vistas a preparar la contratación e informar a los operadores económicos acerca de sus planes y sus requisitos de contratación.

Para ello, los poderes adjudicadores podrán, por ejemplo, solicitar o aceptar el asesoramiento de expertos o autoridades independientes o de participantes en el mercado, que podrá utilizarse en la planificación y el desarrollo del procedimiento de contratación, siempre que dicho asesoramiento no tenga por efecto falsear la competencia y no dé lugar a vulneraciones de los principios de no discriminación y transparencia".

${ }^{44}$ Art. 115 de la LCSP (Consultas preliminares del mercado):

“(...) 2. El asesoramiento a que se refiere el apartado anterior será utilizado por el órgano de contratación para planificar el procedimiento de licitación y, también, durante la sustanciación del mismo, siempre y cuando ello no tenga el efecto de falsear la competencia o de vulnerar los principios de no discriminación y transparencia.

De las consultas realizadas no podrá resultar un objeto contractual tan concreto y delimitado que únicamente se ajuste a las características técnicas de uno de los consultados. El resultado de los estudios y
} 


\section{VINCULACIÓN DE LA PLANIFICACIÓN CON EL PRINCIPIO DE TRANSPARENCIA}

La planificación es positiva tanto para la Administración como para los operadores económicos. Por una parte, la Administración hace el esfuerzo de determinar sus necesidades en un ámbito cualitativo, cuantitativo y temporal y, por otra, los licitadores tendrán un conocimiento con una importante anticipación de cúal va a ser la actividad de la Administración, contribuyendo a una mayor seguridad jurídica.

Como señala la $\mathrm{OCDE}^{45}$, que la contratación pública ejercite una adecuada planificación puede contribuir a que los departamentos analicen sus necesidades y elijan las mejores opciones de forma que se eviten irregularidades o incluso corrupción en los procedimientos.

\section{UNA ADECUADA PLANIFICACIÓN PUEDE REDUCIR EL VOLUMEN DE LOS CONTRATOS MENORES}

En ocasiones las Administraciones Publicas y demás entidades del Sector Público recurren al contrato menor por una inadecuada planificación de la contratación.

La Junta Consultiva de Contratación Administrativa de Canarias, en su Recomendación 1/2018 ha señalado lo siguiente:

"La contratación menor debe ser utilizada para atender aquellas necesidades puntuales, no previsibles y no repetitivas, debiendo procederse por parte de los diferentes órganos de contratación a hacer un esfuerzo para realizar una planificación anual o plurianual de su actividad contractual y utilizar la pluralidad de procedimientos que recoge la LCSP para atender las necesidades de los órganos de contratación cumpliendo con los principios inspiradores de la Ley".

\section{LA TRAMITACIÓN ANTICIPADA DE CONTRATOS}

Es una técnica que puede tener perfectamente encaje dentro de la planificación y programación.

Se regulaba en el Art.110.2 del TRLCSP y ahora en el Art.117.2 LCSP y Disposición Adicional Segunda.

También resulta de interés la Resolución 181/2017 del Tribunal Administrativo de Contratación Pública de la Comunidad de Madrid ${ }^{46}$.

consultas debe, en su caso, concretarse en la introducción de características genéricas, exigencias generales o fórmulas abstractas que aseguren una mejor satisfacción de los intereses públicos, sin que en ningún caso, puedan las consultas realizadas comportar ventajas respecto de la adjudicación del contrato para las empresas participantes en aquellas".

45 Organización para la Cooperación y el Desarrollo Económico (OCDE), La integridad en la contratación Pública. Buenas prácticas de la A a la Z, Instituto Nacional de Administración Pública, Madrid, 2009, pág. 48.

46 "Por tanto, debemos concluir que el momento para apreciar si se ha levantado la condición suspensiva del procedimiento o ya no es posible que se produzca la misma en ningún caso, es el momento de aprobación del presupuesto 2017 o el final del ejercicio. Mientras tanto, sin perjuicio de la facultad del órgano de contratación de renunciar al contrato, sin posibilidad de licitar otros semejantes, o de la 


\section{LA PROGRAMACIÓN ESPECÍFICA EN CADA CONTRATO}

Dentro de la documentación que debe contener el proyecto de obra figura el programa de trabajo ${ }^{47}$, documento que ha figurado en las distintas normas de contratos del siglo $\mathrm{XX}^{48}$.

El Art.208 de la LCSP contempla dentro de los conceptos indemnizables por suspensión del contrato: " $5 .^{\circ}$ Un 3 por 100 del precio de las prestaciones que debiera haber ejecutado el contratista durante el período de suspensión, conforme a lo previsto en el programa de trabajo o en el propio contrato".

\section{FUNCIONES DE LA JUNTA CONSULTIVA DE CONTRATACIÓN PÚBLICA DEL ESTADO EN MATERIA DE PLANIFICACIÓN DE CONTRATOS}

La LCSP confiere atribuciones a la JCCPE para planificar y llevar a cabo procedimientos de contratación ${ }^{49}$.

\section{FUNCIONES DE PLANIFICACIÓN DE TRAGSA}

La LCSP ${ }^{50}$ alude a determinadas y concretas funciones de planificación de TRACSA, siguiendo los antecedentes de la Ley 30/2007, de 30 de octubre, de Contratos del Sector Público y el TRLCSP.

\footnotetext{
licitadora de retirar su oferta, no existe causa adecuada y suficiente para desistir del contrato hasta tanto, como ya se ha indicado, no se apruebe el presupuesto 2017 y efectivamente se carezca de crédito o finalice el ejercicio presupuestario de dicho año.

De todo lo anterior resulta que a juicio de este Tribunal, no queda acreditada la concurrencia en este momento de una causa objetiva de desistimiento contractual, debiendo estimarse el recurso por este motivo, anulándose el acto impugnado".

${ }^{47}$ Art.233 de la LCSP (Contenido de los proyectos y responsabilidad derivada de su elaboración):

"1. Los proyectos de obras deberán comprender, al menos: (...) e) Un programa de desarrollo de los trabajos o plan de obra de carácter indicativo, con previsión, en su caso, del tiempo y coste. (...)".

${ }^{48}$ Art.124.1 e) de la Ley 13/1995; Art.124.1 e) del TRLCAP; Arts.132 y 144 del RGLC; Art.123.1 e) del TRLCSP.

${ }^{49}$ Art.328 de la LCSP (Junta Consultiva de Contratación Pública del Estado):

“(...) 4. Igualmente, la Junta Consultiva de Contratación Pública del Estado elaborará y remitirá a la Comisión Europea cada tres años un informe referido a todos los poderes adjudicadores estatales, autonómicos y locales que, respecto de la licitación pública y ejecución de los contratos de obras, suministros, servicios, concesión de obras y concesión de servicios que estén sujetos a regulación armonizada, comprenda, entre otras, si procede, las siguientes cuestiones: (...) e) Información sobre las iniciativas adoptadas para proporcionar orientación o ayuda gratuita en la aplicación de la normativa de la Unión Europea en materia de contratación pública o para dar respuesta a las dificultades que plantee su aplicación, así como para planificar y llevar a cabo procedimientos de contratación".

50 Disposición Adicional Vigésima Cuarta de la LCSP (Régimen jurídico de la «Empresa de Transformación Agraria, S. A., S. M. E., M. P.» (TRAGSA), y de su filial «Tecnologías y Servicios Agrarios, S. A., S. M. E., M. P.» (TRAGSATEC):

“(...) 4. TRAGSA y su filial TRAGSATEC prestarán, por encargo de las entidades del sector público de los que son medios propios personificados, las siguientes funciones:
} 


\section{CONCLUSIONES}

1. Resulta muy positivo que en la LCSP se recoja expresamente la obligación de aprobar un Plan de Contratación y de programar la actividad contractual.

2. La redacción del Art.28 de la LCSP debería concretarse y desarrollarse, por vía reglamentaria, en cuanto al contenido, plazos y calendario de esa programación y al procedimiento de aprobación del plan de Contratación, pues el Art.28 se remite al 134 y éste al Anexo III.

3. Debería hacerse extensiva la publicación del Plan de Contratación a toda la planificación de la contratación, no sólo los contratos sujetos a regulación armonizada.

4. La publicación del Plan de Contratación contribuye a una mayor transparencia en la contratación.

5. La modificación del plan de Contratación debe efectuarse por causas justificadas y no a imprevisiones.

6. La programación contribuye a lograr una mayor eficacia y eficiencia y a racionalizar los contratos públicos, estudiando qué contratos se pueden dividir en lotes.

7. La adecuada planificación permitirá que contratos que se realizan de manera reiterada utilizando el contrato menor se puedan adjudicar a través de procedimientos abiertos.

8. La planificación debe incluir el estudio de los aspectos sociales y medioambientales de los contratos.

9. La planificación permitirá determinar los ámbitos en que se desarrollarán los contratos reservados.

10. Deberían establecerse cuáles son las consecuencias y efectos de la falta de aprobación del Plan y de la programación.

11. Se deben realizar estudios de evaluación del Plan de Contratación y la eficacia y alcance del mismo para estudiar las mejoras y rectificar los puntos débiles del mismo.

g) La planificación, organización, investigación, desarrollo, innovación, gestión, administración y supervisión de cualquier tipo de servicios ganaderos, veterinarios, de seguridad y sanidad animal y alimentaria.

(...) TRAGSA y su filial TRAGSATEC también estarán obligadas a satisfacer las necesidades de las entidades del sector público de las que son medios propios personificados en la consecución de sus objetivos de interés público mediante la realización, por encargo de los mismos, de la planificación, organización, investigación, desarrollo, innovación, gestión, administración y supervisión de cualquier tipo de asistencias y servicios técnicos en los ámbitos de actuación señalados en el apartado anterior, o mediante la adaptación y aplicación de la experiencia y conocimientos desarrollados en dichos ámbitos a otros sectores de la actividad administrativa. (...)". 


\section{BIBLIOGRAFÍA}

ARNÁEZ ARCE, V. M., La potestad planificadora de las Administraciones Públicas, Editorial Gomylex, 2013.

MARTÍN-RETORTILLO, S., “Antecedentes del concepto de plan y referencia a la legislación de fomento del siglo XX”, RAP, n49, enero-abril 1966.

MARTÍN-RETORTILLO, S., Derecho administrativo económico, Tomo I, La Ley, 1988.

MEILÁN GIL, J.L., "Unidad del contrato público e interés general: itinerario de una investigación”, Revista General de Derecho Administrativo, nº48, Iustel, mayo 2018.

Organización para la Cooperación y el Desarrollo Económico (OCDE), La integridad en la contratación Pública, Buenas prácticas de la $A$ a la Z, Instituto Nacional de Administración Pública, Madrid, 2009.

RODRÍGUEZ FERNÁNDEZ, L.J., "Reflexiones sobre la contratación en el ordenamiento jurídico español a la luz de las nuevas Directivas europeas de Contratación y Anteproyecto de ley de contratos del sector público", en AAVV., Cuadernos de Mariñán.2016, IX Jornadas de Derecho Administrativo Iberoamericano “Contratación, Ordenación del Territorio y Buena Administración”, Editorial Deputación Provincial da Coruña, 2018. 